\title{
Successful closure of the root apex in non-vital permanent incisors with wide open apices using single calcium hydroxide (caoh) dressing - report of 2 cases
}

\author{
NB Nagaveni ${ }^{1}$, KV Umashankara ${ }^{2}$, NB Radhika ${ }^{3}$, S Manjunath ${ }^{4}$
}

${ }^{1}$ M.D.S., Assistant professor, Department of Pedodontics and Preventive dentistry, College of Dental Sciences, Davangere, India. ${ }^{2}$ M.D.S., Associate professor, Department of Oral and Maxillofacial surgery, College of Dental Sciences, Davangere, India.

${ }^{3}$ M.D.S., Senior lecturer, Department of Orthodontics, D. Y. Patil Dental College \& Hospital Pune, Maharashtra.

${ }^{4}$ M.D.S., Professor, Department of Oral and Maxillofacial surgery, College of Dental Sciences, Davangere, India.

\section{Correspondence:}

Dr. Nagaveni N. B. M. D. S.,

Assistant professor

Department of Pedodontics and Preventive dentistry

College of Dental Sciences,

Davangere, Karnataka, India

E-mail: nagavenianurag@gmail.com

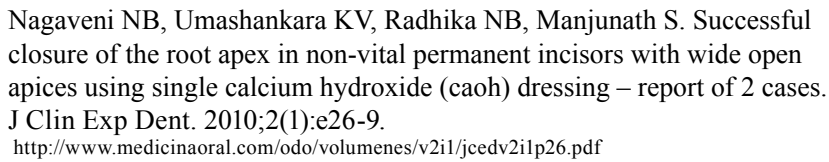

Nagaveni NB, Umashankara KV, Radhika NB, Manjunath S. Successful closure of the root apex in non-vital permanent incisors with wide open apices using single calcium hydroxide (caoh) dressing - report of 2 cases. J Clin Exp Dent. 2010;2(1):e26-9.

http://www.medicinaoral.com/odo/volumenes/v2i1/jcedv2i1p26.pdf

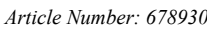

\begin{abstract}
Endodontic management of immature non vital permanent teeth in young pediatric patients is a great challenge to dentists. The walls of the root canals are frequently divergent and open apexes make debridement and obturation difficult. Thus closure of root apex is very essential for success of the endodontic treatment. Although different materials are used for the apexification procedure, calcium hydroxide is the material of choice for apical barrier formation and healing. There are different opinions regarding frequency of $\mathrm{CaOH}$ dressing change to induce complete closure of the apex. Literature suggests that dressing should be changed frequently. Therefore the aim of the present article is to report the successful closure of root apex in pulpless permanent incisors with wide open apices in two pediatric patients using single $\mathrm{CaOH}$ dressing.
\end{abstract}

Key words: Calcium hydroxide, apical closure, open apex, immature teeth. 


\section{Introduction}

Dental trauma in young permanent tooth may lead to nonvitality, if not intervened at an early stage. The treatment of non-vital immature teeth is a great challenge to clinician, as the root formation has not completed and open apex is found in the developing roots of immature teeth, which closes approximately 3 years after eruption of the tooth. For condensing gutta-percha, there should be an apex barrier to prevent extrusion of cement and guttapercha into the periapical area causing trauma to the periapical tissues. Apexification is defined as "a method to induce a calcified barrier in a root with an open apex or the continued apical development of an incomplete root in teeth with necrotic pulp" (1). The most common medicament used for this technique is the $\mathrm{CaOH}$. The average time taken for apexification to complete using $\mathrm{CaOH}$ is $5-20$ months $(2,3)$. So in this period, how frequently the $\mathrm{CaOH}$ dressing should be changed is a controversy in the endodontic literature. Majority of studies have suggested that, the initial change should be at 1 month and subsequent 3-month intervals (4), while others advocate changing at 1 month and again at 6-8 month intervals until apical barrier formation takes place (5). But there is a report which shows that, just a single dressing with $\mathrm{CaOH}$ is enough to form apical barrier in non-vital immature teeth, when there is a favorable condition exists such as bacteria free environment (6).

The aim of the present article is to present two cases, showing apical barrier formation occurring in a nonvital permanent incisor with wide open apices using a single $\mathrm{CaOH}$ dressing.

\section{Case reports}

\section{Case 1}

An 11-year-old female patient reported complaining of pain in the upper front tooth since 1 week. There was a history of trauma to the same tooth due to fall about 2 years back. On clinical examination, Elli's class IV fracture in permanent maxillary right central incisor was evident. Periapical radiograph showed incomplete root formation with wide open apices for the same tooth (Fig.1). Apexification with $\mathrm{CaOH}$ dressing was planned. In the first visit, an access cavity was prepared with a straight line entry into the root canal. The working length was established within $1 \mathrm{~mm}$ of the radiographic apex by using size 30 Hedstrom file. Next, complete debridement of canal was done using $\mathrm{H}$ file number 40 followed by copious irrigation with normal saline. After drying of the canal using paper points, $\mathrm{CaOH}$ powder was mixed with normal saline and this mixture was placed into the canal and pushed to the short of apex using plugger. Access opening was restored with glass ionomer cement. Patient was called after 3 months. But unfortunately patient did not turn up. But after 7 months when patient came back, a periapical radiograph was taken, which

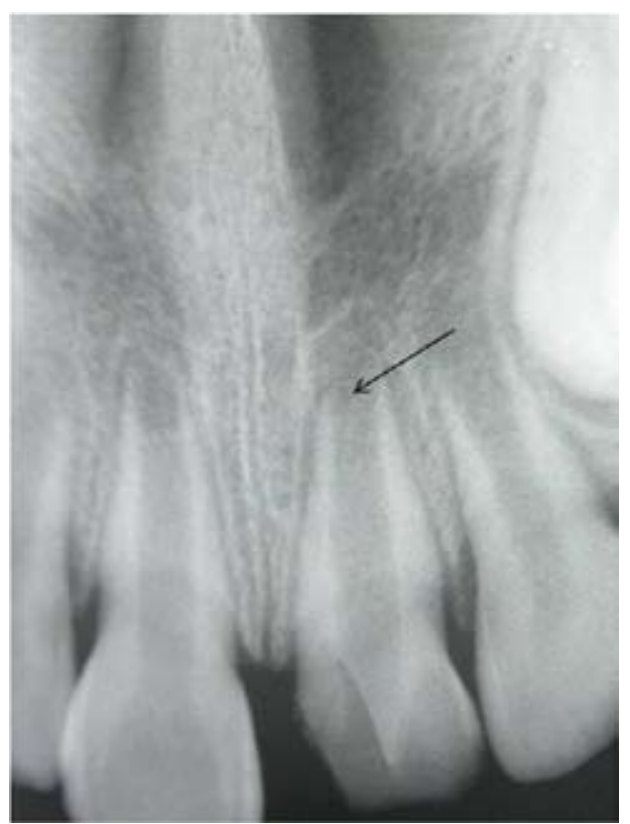

Fig.1. Periapical radiograph showing wide open apex in relation to 21 (arrow)

showed complete formation of the root apex in maxillary right central incisor, without any signs and symptoms and periapical radiolucency (Fig.2).

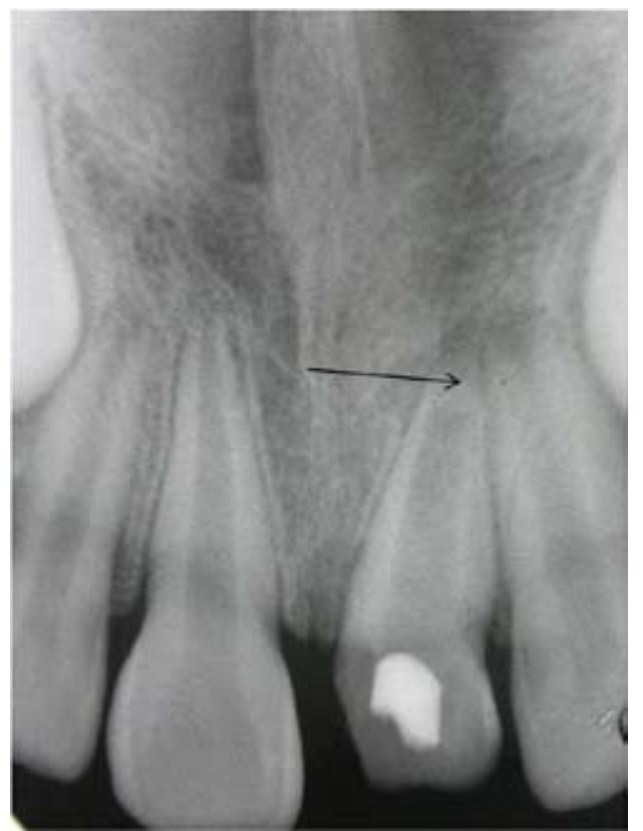

Fig.2. Periapical radiograph taken after 7 months shows closure of the apex (arrow) with no periapical changes and loss of coronal restoration

Clinically apical barrier formation was confirmed by using a size 30 paper point to check for the presence of a resistant 'stop' and absence of hemorrhage, exudates or sensitivity. In the next visit, complete obturation was done using thermoplasticized gutta-percha technique (Fig.3) followed by post and core fabrication. 


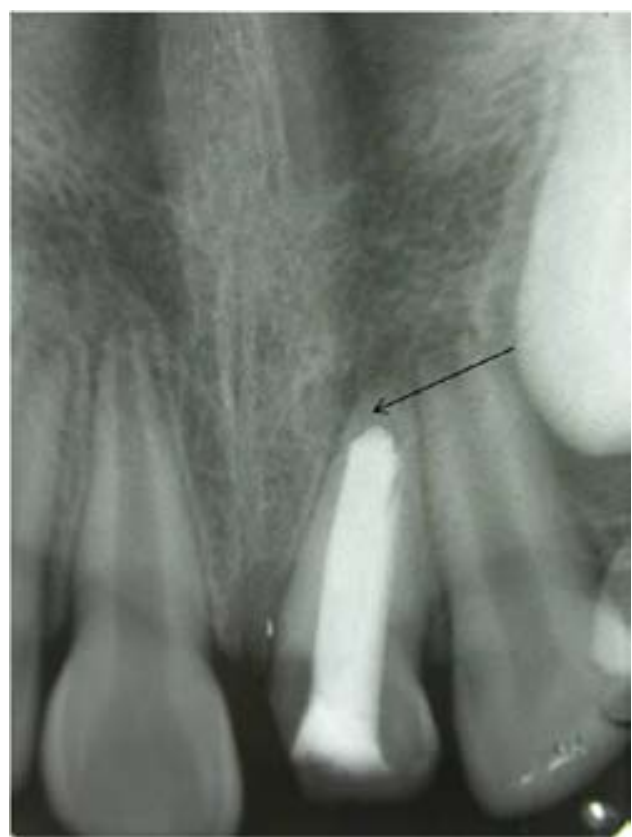

Fig. 3. Photograph showing complete obturation of 21

\section{Case 2}

A 10-year-old female patient reported complaining of pain in the upper front tooth since 4 days. There was a previous history of trauma to the same tooth 1 year back. Clinical examination revealed Elli's class IV fracture in relation to permanent maxillary left central incisor. On radiographic examination, wide open apex with thin dentinal wall was found in relation to the same tooth (Fig. 4). Apexification with $\mathrm{CaOH}$ was planned. The same treatment procedure was performed as like in case 1. Patient called every month to check radiographically

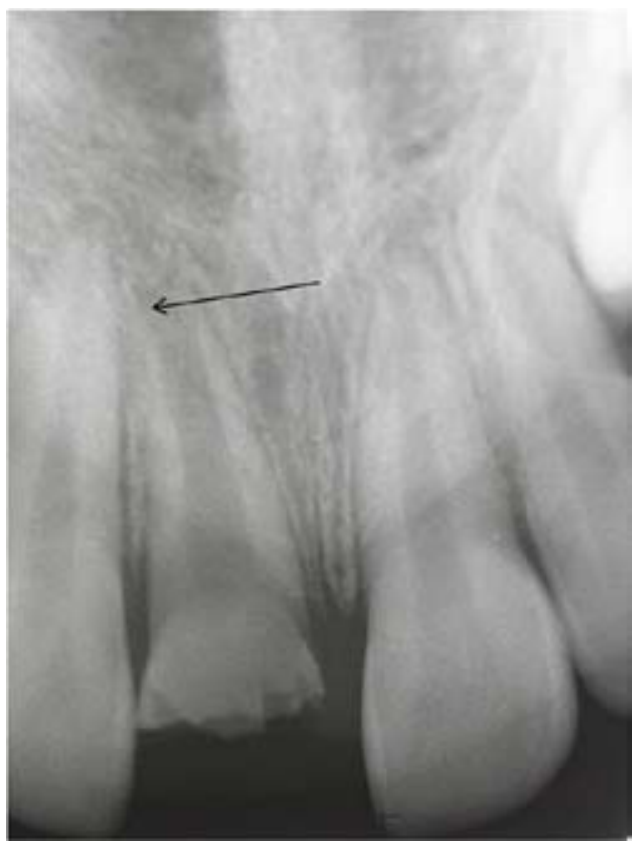

Fig. 4. Radiograph showing wide open apex with thin dentinal walls in relation to 11 (arrow) for the closure of the apex. In each visit on radiographic examination, positive changes were noticed. After 6 months there was a complete closure of the apex (Fig. 5), which was confirmed clinically by using paper point and after the confirmation of the barrier formation, the conventional obturation was done (Fig. 6).

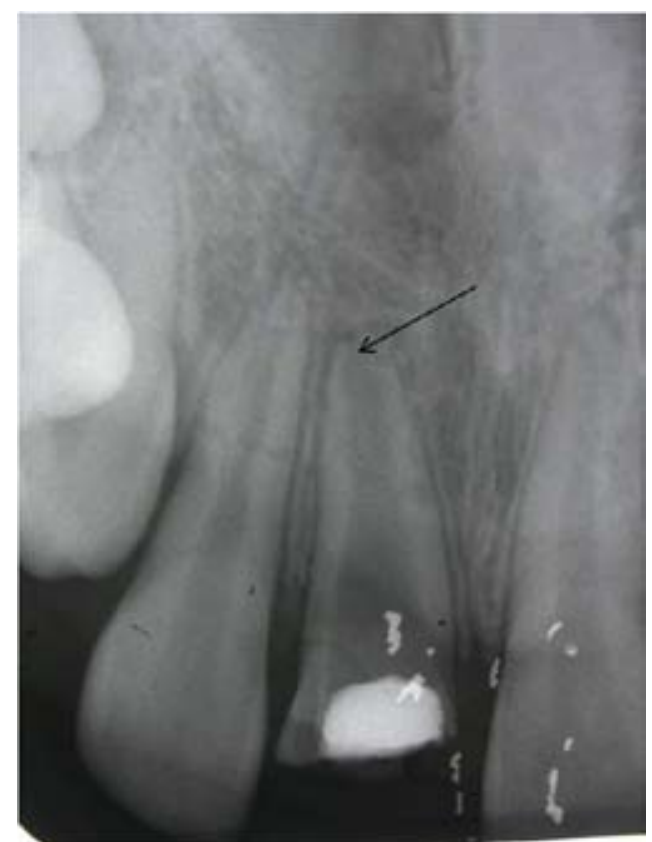

Fig. 5. Radiograph showing complete formation of the apex (arrow)

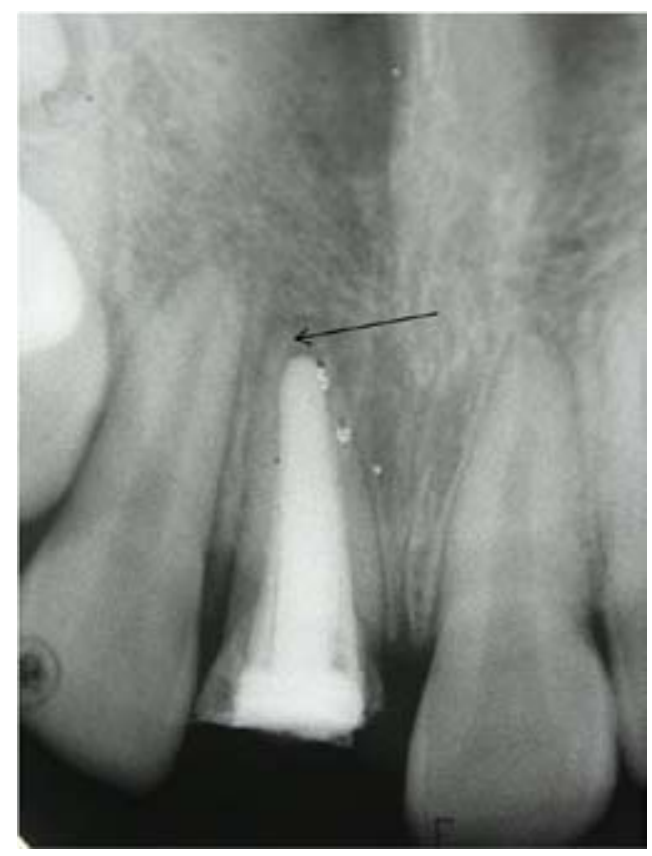

Fig. 6. Radiograph taken after 6 months showing complete obturation of 11

\section{Discussion}

In the literature many other materials have been used for apexification, such as calcium hydroxide in combi- 
nation with sterile water, saline, local anesthetic, camphorated parachlorophenol, zinc oxide paste with cresol and iodoform (7), polyantibiotic paste (8) and tricalcium phosphate (9). There are new strides in the apexification procedure with mineral trioxide aggregate (MTA) (10). But the use of $\mathrm{CaOH}$ in apical barrier formation has shown promising results. Because of its enhanced success rate, easy availability for clinician and affordability for patients, it has gained widest acceptance in the literature.

The alkalinity of non setting $\mathrm{CaOH}$ is used to stimulate the formation of mineralized and fibrous tissue by the granulation tissue cells in the apical part of the root canal (11). It stimulates the physical barrier and also acts as disinfectant. The resultant mineralized tissue can be composed of osteocementum, osteodentine, or bone or some combination of the three. The calcific bridge can be a complete or an incomplete hard tissue bridge at the root end or a few millimeters short of it.

Chawla (6) has suggested that the amount of $\mathrm{CaOH}$ in the single root canal dressing was sufficient to initiate and complete the bridge in $92.3 \%$ of the teeth in his study. Chosack et al. (12) suggested that repeated root filling are not required as $\mathrm{CaOH}$ is only required to initiate healing process. They also reported that the $\mathrm{CaOH}$ has to be replaced if there are any symptoms or displacement of the medicament.

The frequency of $\mathrm{CaOH}$ dressing change is one of the few variables within the operator's control, which also has an effect on the speed of barrier formation. There are number of studies $(11,13)$ showing that, when the frequency of change was low, rapid barrier formation was seen and there were also some studies where the frequency of change was high, there was slow barrier formation. Hence it is confirmed that, if the root apex is disturbed by repeated instrumentation and dressing changes, then the time required for apex formation prolongs (14). Thus a single dressing is enough to induce the apical barrier formation.

The present two case reports throw light on apical end closure in immature non-vital permanent incisors using a simple technology of $\mathrm{CaOH}$ apexification. It is concluded that single application of $\mathrm{CaOH}$ dressing is sufficient to induce apical barrier formation in young pediatric patients having pulpless teeth with wide open apices. As the sample size is less, it requires further study with long term follow up on more number of teeth, to rule out complications such as recurrence of infection and cervical root fracture.

\section{References}

1. Sheely EC, Roberts GJ. Use of calcium hydroxide for apical barrier formation and healing in non-vital immature permanent teeth: A review. Br Dent J. 1997;183: 241-6.

2. Kleier DJ, Barr ES. A study of endodontically apexified teeth. Endod Dent Traumatol. 1991;7:112-7.

3. Mackie IC, Bentley EM, Worthington HV. The closure of open api- ces in non-vital immature incisor teeth. Br Dent J. 1988;162:169-73. 4. Mackie IC. UK National Clinical Guidelines in Paediatric Dentistry. Management and root canal treatment of non-vital immature permanent incisor teeth. Faculty of Dental Surgery, Royal College of Surgeons. Int J Paediatr Dent. 1998;8:289-93.

5. Ghose LJ, Baghdady VS, Hikmat M. Apexification of immature apices of pulpless permanent anterior teeth with calcium hydroxide. J Endod. 1987;13:285-90.

6. Chawla HS. Apical closure in a nonvital permanent tooth using one $\mathrm{Ca}(\mathrm{OH}) 2$ dressing. ASDC J Dent Child. 1986;53:44-7.

7. Cooke C, Rowbotham TC. 'The closure of open apices in non-vital immature incisor teeth'. Br Dent J. 1988;165:420-1.

8. Rule DC, Winter GB. Root growth and apical repair subsequent to pulpal necrosis in children. Br Dent J. 1966;120:586-90.

9. Coviello J, Brilliant JD. A preliminary clinical study on the use of tricalcium phosphate as an apical barrier. J Endod. 1979;5:6-13.

10. Shabahang S, Torabinejad M, Boyne PP, Abedi H, McMillan P. A comparative study of root-end induction using osteogenic protein-1, calcium hydroxide, and mineral trioxide aggregate in dogs. J Endod. 1999;25:1-5.

11. Vojinović O. Induction of apical formation in immature teeth by different endodontic methods of treatment. Experimental pathohistological study. J Oral Rehabil. 1974;1:85-97.

12. Chosack A, Sela J, Cleaton-Jones P. A histological and quantitative histomorphometric study of apexification of nonvital permanent incisors of vervet monkeys after repeated root filling with a calcium hydroxide paste. Endod Dent Traumatol. 1997;13:211-7.

13. De-Deus G, Coutinho-Filho T. The use of white Portland cement as an apical plug in a tooth with a necrotic pulp and wide-open apex: a case report. Int Endod J. 2007;40:653-60.

14. Kinirons MJ, Srinivasan V, Welbury RR, Finucane D. A study in two centres of variations in the time of apical barrier detection and barrier position in nonvital immature permanent incisors. Int J Paediatr Dent. 200;11:447-51. 